\title{
ANALISA QoS (QUALITY OF SERVICE) PADA JARINGAN RT-RW NET DENGAN KENDALI RASPBERRY PI
}

\author{
Adi Fajaryanto Cobantoro ${ }^{1)}$ \\ 1) Program Studi Teknik Informatika, Fakultas Teknik, Universitas Muhammadiyah Ponorogo \\ Jl Budi Utomo no 10, Ponorogo \\ Email : adifajaryanto@umpo.ac.id ${ }^{1)}$
}

\begin{abstract}
Abstrak
Perkembangan $R T R W$ Net saat ini meningkat pesat.Penyebaran akses internet pada $R T R W$ Net dilakukan dengan memanfaatkan teknologi nirkabel melalui access point. Dengan banyaknya akses point maka penyebaran internet semakin luas, namun hal tersebut berdampak pada menurunnya bandwidth yang didapat oleh client. Hal ini disebabkan oleh alokasi bandwidth dari pihak provider terbatas. Untuk mengatasi hal tersebut maka dibutuhkan sebuah server proxy untuk menghemat bandwidth, salah satu dari proxy yang handal yaitu proxy squid. Server berupa komputer PC yang mempunyai ukuran yang besar, yang penempatannya membutuhkan ruang tersendiri. Raspberry Pi merupakan komputer mini yang performanya setara dengan komputer PC. Server dengan ukuran mini tentu akan mempermudah pemasangan pada pemancar acces point $R T-R W$ net. Server mini dapat dibangun menggunakan Raspberry Pi sehingga akan lebih portable dalam penempatannya. Dilakukan pengukuran Quality of Service, yaitu packet loss, delay, jitter dan throughput pada proxy raspberry pi. Berdasarkan Telecommunications and Internet Protocol Harmonization Over Networks (TIPHON), hasil analisa QoS Raspberry Pi termasuk kategori baik.
\end{abstract}

Kata kunci : raspberry pi, internet, server, network, proxy

\begin{abstract}
The development of $R T R W$ Net currently is increasing rapidly. The spread of internet access on $R T R W$ Net is done by utilizing wireless technology through access point. With the number of access points then the spread of the internet is more widespread, but it affects the decreased bandwidth obtained by the client. This is due to the bandwidth allocation of the limited provider. To overcome this it takes a proxy server to save bandwidth, one of the reliable proxy is squid proxy. Server is a PC computer that has a large size, which placement requires a separate space. Raspberry Pi is a mini computer that performs the equivalent of a PC computer. Servers with mini size will certainly facilitate the installation of RT-RW net access point transmitter. Mini servers can be built using Raspberry Pi so it will be more portable in its placement. Performed Quality of Service measurement, ie packet loss, delay, jitter and throughput on the raspberry proxy pi. Based on Telecommunications and Internet Protocol Harmonization Over Networks (TIPHON), the QoS Raspberry Pi analysis is good.
\end{abstract}

Keywords : raspberry pi, internet, server, network, proxy

\section{Pendahuluan}

Penerapan teknologi jaringan komputer berkembang seiring perkembangan teknologi informasi. Teknologi jaringan komputer juga dapat dimanfaatkan untuk menyediakan internet yang akan menghubungkan antar pengguna komputer. Saat ini internet merupakan sumber informasi utama masyarakat disamping juga untuk melakukan transaksi [2]. Penyebaran akses internet di masyarakat biasanya menggunakan jaringan RT-RW net, RT-RW net adalah jaringan 
internet dengan memanfaatkan komunitas pada lingkungan tertentu. Pada jaringan RT-RW net penyebaran koneksi dilakukan menggunakan access point yang dipancarkan ke segala arah. Untuk menambah jangkauan dapat dilakukan dengan menambah access point menjadi beberapa titik pancaran. RT-RW net memiliki kendala yaitu semakin banyak titik access point maka berdampak maka penyebaran bandwidth yang tidak merata, hal ini sebagai akibat konfigurasi dari provider yang terkunci default. Untuk mengatasi hal ini maka perlu adanya pengaturan bandwidth di RT-RW net yang dikelola. Proses pengaturan ini dapat dilakukan dengan menggunakan Server. Server adalah sebuah komputer yang memberikan layanan tertentu kepada komputer client pada sebuah jaringan komputer, dan dapat mendukung kinerja sebuah jaringan. Agar kinerja Server baik diperlukan keamanan pada proxy, pengaturan bandwidth, dan cache pada jaringan. Server biasanya memiliki ukuran layaknya sebuah komputer personal (PC). Ukuran yang besar ini dalam penempatannya membutuhkan ruang tersendiri yang belum tentu tersedia. Server dengan ukuran mini tentu akan mempermudah pemasangan pada pemancar accesspoint RT-RW net. Server mini dapat dibangun menggunakan Raspberry Pi sehingga akan lebih portable dalam penempatannya.

Raspberry Pi adalah mini komputer berupa SoC (Sistem on chip) yang menyediakan fungsifungsi komputer serta elektronika ke dalam satu board atau bisa juga disebut dengan embbedded system[3]. Raspberry Pi yang telah ter-install sistem operasi open source bernama raspbian jessie dapat dipasangi aplikasi proxy. Proxy merupakan sebuah program komputer yang berperan sebagai penghubung antara suatu komputer dengan jaringan internet maupun intranet, serta dapat meningkatkan kinerja koneksi RT-RW net dengan optimalisi bandwidth [4]. Untuk dapat mengoptimasi bandwidth maka diperlukan analisa Quality of Service (QoS) dari sebuah perangkat raspberry pi. Kapasitas suatu jaringan komputer untuk membagikan servis yang baik dengan menyiapkan layanan data, menangani jitter dan delay. Faktor-faktor yang akan diukur pada penelitian ini yaitu delay, packetloss, jitter dan throughput. QoS digunakan untuk mengukur kualitas layanan data yang digunakan. Faktor yang dapat mempengaruhi nilai QoS, yaitu: redaman, distorsi, dan noise. Packetloss merupakan keadaan yang menginformasikan besaran bagian yang tertinggal. Bagian tersebut dapat terjadi karena benturan antar data dan antrian data pada jaringan komputer. Benturan ini berdampak pada seluruh aplikasi, Hal ini karena munculnya proses transmisi ulang yang akan memangkas tingkat efisiensi jaringan komputer secara global. Meskipun jumlah layanan data tersedia dengan layak untuk aplikasi-aplikasi tersebut. Durasi yang dibutuhkan data untuk melintasi dari awal menuju tujuan akhir disebut Delay. Delay berpengaruh pada jarak, saluran fisik, dan penumpukan data sehingga membutuhkan waktu yang panjang. Jitter umumnya disebut variasi delay, berkaitan kuat dengan latency, yang memperlihatkan jumlah varietas delay pada transmisi data di jaringan komputer. Delay pada router dan switch, yang biasanya disebabkan oleh proses antrian data, dapat menyebabkan timbulnya jitter. Throughput melambangkan ukuran yang aktual dari suatu jaringan komputer dalam proses pengiriman data. Throughput dan bandwidth tidak dapat dipisahkan. Throughput bisa disebut dengan bandwidth dalam kondisi yang sebenarnya namun bandwidth cenderung statis sementara throughput bersifat dinamis, tergantung pada lalu lintas data yang sedang terjadi. Berdasarkan latar belakang diatas, maka dilakukan analisa Quality of Service (QoS) pada layanan proxy berbasis raspberry pi.

\section{Tinjauan Pustaka}

\subsection{Jaringan}

Jaringan komputer (Computer Network) adalah gabungan komputer dan perangkat lain yang terhubung satu dengan yang lain menggunakan media komunikasi tertentu. Informasi yang melewati perangkat komunikasi, mengijinkan pemakai jaringan untuk saling bertukar data atau 32 | NERO 
memanfaatkan software maupun hardware secara sharing[5]. Masing-masing komputer atau alat-alat lain yang dihubungkan pada jaringan disebut node. Jaringan dapat terdiri dari puluhan, ratusan atau bahkan ribuan node. Jaringan komputer dapat dimanfaatkan pada berbagai kebutuhan untuk memberikan keringanan dalam menyelesaikan sebuah pekerjaan[4]. Dalam implementasinya, terdapat dua jenis hubungan dalam jaringan komputer, yaitu dengan menggunakan kabel dan dengan tanpa menggunakan kabel (yang selanjutnya disebut dengan wireless) [5].

\subsection{Raspberry Pi}

Raspberry Pi adalah komputer yang berukuran sebesar kartu kredit yang dapat dihubungkan ke monitor komputer atau TV, dan menggunakan keyboard standar dan mouse. Raspberry Pi adalah perangkat kecil yang mampu mengenali program dalam berbagai bahasa seperti Scratch dan Python. Raspberry Pi memiliki kemampuan untuk berinteraksi dengan dunia luar, dan telah digunakan dalam berbagai macam proyek pembuat digital, dari mesin musik dan detektor orangtua untuk cuaca stasiun dan tweeting rumah burung dengan kamera infra-merah.

Raspberry Pi memiliki fungsi serupa dengan komputer pada umumnya. Ada bagian USB untuk memasukkan keyboard, mouse, dan slot HDMI. Terdapat 2 model pada raspberry pi, model A dan model B. Beberapa perbedaan diantara keduanya terletak padaukuran memori (512 MB pada model A dan $1 \mathrm{~Gb}$ pada model B) serta ketersediaan network adaptor yang hanya ada pada model B. Raspberry pi hanya membutuhkan daya 3,5 watt[6].

\subsection{Proxy}

Pada lingkup jaringan komputer, komputer yang bertindak sebagai proxy merupakan komputer Server yang berlaku sebagai penghubung untuk membantu klien yang mencari informasi atau sumber daya dari Server lain. Server proxy akan menghubungi Server yang memiliki sumber daya dan meminta data yang diminta oleh klien, dengan cara ini Server yang memiliki data hanya mengetahui bahwa yang meminta datanya adalah Server proxy. Sebuah proxy server memiliki dua tujuan :

- Untuk menjaga mesin dibaliknya anonymous atau tak dikenali (terutama untuk alasan keamanan) baik yang meminta maupun penyedia layanan

- Untuk mempercepat akses ke sumber daya (caching). Biasanya digunakan untuk cache halaman web dari web Server.

Server proxy sering juga disebut web proxy akan mengatur HTTP Request menuju Server website di internet atas request dari komputer user. Sehingga web Server akan mengetahui bahwa yang melakukan request adalah proxy Server dan bukan komputer user. Dengan kata lain, proxy akan menerima permintaan HTTP dari komputer klien, kemudian proxy akan membuat HTTP request atas nama dirinya sendiri kepada Server website. Server website menerima HTTP Request tadi dan memberikan HTTP Request kepada proxy yang selanjutnya akan diteruskan menjadi HTTP response dari web Server kepada user yang melakukan request awal[5].

\section{Metodologi Penelitian}

Metodologi penelitian yang digunakan dalam penelitian ini yaitu seperti gambar 1 . 


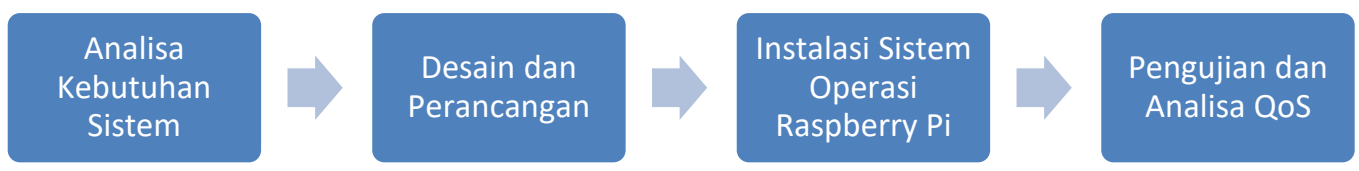

Gambar 1. Metodologi Penelitian

\subsection{Analisa Kebutuhan Sistem}

Proses analisis kebutuhan sistem yang akan dilakukan adalah kegiatan penggalian informasi terkait kebutuhan pengguna, kebutuhan sistem dan konfigurasi sistem kebutuhan pengguna (user requirements), daftar user requirements diperoleh dengan melakukan survei ke lapangan dengan metode wawancara. Pengumpulan data peneliti lakukan dengan berbagai macam cara, yaitu :

- Pengamatan dilakukan dengan teknik yang dipergunakan dalam pengumpulan data bersumber pada pemantauan secara langsung terhadap obyek yang hendak diteliti.

- Dokumentasi (Documentation) adalah suatu cara pengumpulan data dengan cara mendokumentasikan apa yang peneliti ketahui baik itu dari hasil wawancara maupun dari hasil observasi.

\subsection{Desain dan Perancangan}

Pada tahapan ini dilakukan proses desain dan perancangan topologi yang akan dimodelkan untuk mendukung penelitian ini.

\subsection{Instalasi Sistem Operasi Raspberry Pi}

Tahap ini dilakukan instalasi Raspbian whezzy, implementasi dan konfigurasi proxy squid dari mikrokomputer Raspberry Pi agar dapat mendukung menjadi Server proxy.

\subsection{Pengujian dan Analisa QoS}

Tahap ini dilakukan pengujian QoS (Quality of Service) terhadap perangkat raspberry pi yang telah dikonfigurasi proxy squid. Pengujian dan analisa QoS menggunakan aplikasi wireshark. Parameter yang diuji yaitu packet loss, jitter, delay, dan throughput. Setelah tahap pengujian selesai maka raspberry pi akan diimplementasikan pada model RT RW Net.

\section{Pembahasan}

Pada tahap ini dilakukan pengujian terhadap perangkat raspberry pi yang telah dikonfigurasi proxy squid dengan metode analisa QoS untuk mengetahui kualitas suatu jaringan. Analisa Quality of Service dilakukan dengan menghitung nilai setiap parameter pada protokol udp dengan menggunakan tool wireshark untuk membantu proses pengamatan protokol. Dengan menggunakan tool wireshark yang mampu menangkap semua paket yang melewati jaringan yang diamati. Parameter delay, packet loss, troughput, dan jitter akan digunakan sebagai indikator QoS pada protokol udp. Tabel User dan Perhitungan parameter QoS pada protokol udp sebagai berikut :

\begin{tabular}{|c|c|c|c|c|c|c|c|c|c|c|}
\hline Pelanggan & User A & User B & User C & User D & User E & User F & User G & User H & User I & User J \\
\hline Ip Address & $61,61,61.28$ & $61,61,61.102$ & $61,61,61.109$ & $61,61,61,55$ & $61,61.61,38$ & $61,61,61,112$ & $61,61,61.111$ & $61,61,61.34$ & $61,61,61,30$ & $61,61,61,13$ \\
\hline
\end{tabular}

Gambar 2. User 
Dilakukan analisa Quality of Service terhadap packet loss, jitter, delay dan throughput dengan menggunakan rumus pada tabel 1 .

Tabel 1. Rumus perhitungan QoS

\begin{tabular}{|l|c|}
\hline \multicolumn{1}{|c|}{ Quality of Service } & Rumus \\
\hline Packet loss & $\frac{\text { (paket data dikirim - paket data diterima) }}{\text { paket data dikirim }} \times 100 \%$ \\
\hline Delay & waktu paket dikirim - waktu paket diterima \\
\hline Jitter & $\frac{\text { jumlah data yang dikirim }}{\text { waktu pengiriman data }}$ \\
\hline Troughput & \\
\hline
\end{tabular}

Hasil perhitungan analisa QoS user A sampai user J dapat dilihat pada tabel 2 dibawah ini.

Tabel 2. Tabel hasil analisa QoS

\begin{tabular}{|l|l|l|l|l|}
\hline \multicolumn{1}{|c|}{ User } & Packet loss (\%) & \multicolumn{1}{c|}{ Delay $(\mathbf{m s})$} & Jitter $(\mathbf{m s})$ & Throughput (kbps) \\
\hline A & 1,35 & 0,010 & 0,0003000 & 0,0200 \\
\hline B & 0 & 0,480 & 0,0002000 & 0,0005 \\
\hline C & 0 & 0,530 & 0,0004700 & 0,0004 \\
\hline D & 0,8 & 0,030 & 0,0010000 & 0,0065 \\
\hline E & 0,4 & 0,004 & 0,0000003 & 0,0660 \\
\hline F & 1,3 & 0,006 & 0,0018900 & 0,0240 \\
\hline G & 0,7 & 0,007 & 0,0000400 & 0,0230 \\
\hline H & 0 & 0,001 & 0,0000020 & 0,0230 \\
\hline I & 1,47 & 0,001 & 0,0003000 & 0,0250 \\
\hline J & 0 & 0,003 & 0,0006000 & 0,0090 \\
\hline
\end{tabular}

\section{Kesimpulan}

Dari hasil pengujian dengan menggunakan parameter QoS seperti delay, jitter, packet loss, dan throughput dapat dikesimpulkan bahwa penggunaan raspberry pi sebagai mini Server pada jaringan RT/RW Net tergolong pada kategori QoS baik [1] dari empat parameter uji yaitu :

a. Packet Loss : parameter packet loss pada jaringan Rt Rw Net tergolong pada kualitas yang bagus dengan nilai rata-rata $0 \%$

b. Delay : Parameter delay pada jaringan Rt Rw Net tergolong pada kualitas yang bagus dengan nilai rata-rata $0,1 \mathrm{~ms}$

c. Jitter : Parameter Jitter pada jaringan Rt Rw Net tergolong pada kualitas jaringan yang bagus dengan nilai rata-rata $0,000489228 \mathrm{~ms}$

d. Throughput : Parameter throughput pada jaringan Rt Rw Net dengan rata-rata 0,01974 kbps

\section{Daftar Pustaka}

[1] Wagito, Jaringan Komputer, Teori dan Implementasi berbasis Linux. Jakarta: Gava Media, 2007.

[2] T. Ernawati, "Analisis dan Pembangunan Infrastruktur Cloud Computing," $J$. Cybermatika, Vol. 1, No. 2, pp. 17-23, 2013.

[3] A. F. Cobantoro, "Rekayasa Web Proxy Pada Komputer Mikro Untuk Keamanan Anak 
Dalam Berinternet," in Seminar Nasional dan Gelar Produk, 2017.

[4] F. Masykur and J. Karaman, "PENERAPAN WEB PROXY GUNA MENDUKUNG SISTEM," in Seminar Nasional Telekomunikasi dan Informatika, 2016, pp. 158-163.

[5] R. Towidjojo, Mikrotik Kungfu Kitab 1. Jasakom.com, 2016.

[6] Hareendran, "Arduino and raspberry pi camera interface." [Online]. Available: www.electroschematics.com. [Accessed: 21-Jul-2017]. 